\title{
Synthesis, Crystallographic and Magnetic Properties of Mn Doped ZnO Nanocrystals Via Solid State Reaction Technique
}

\author{
V. D. Mote ${ }^{1}$, B. N. Dole ${ }^{2, *}$ \\ ${ }^{1}$ Department of Physics, Dayanand Science College, Latur-413512, India \\ ${ }^{2}$ Advance Materials Research Lab., Dept. of Physics, Dr. B. A. Marathwada, University, Aurangabad - 431 004, India \\ *Corresponding Author: drbndole@yahoo.com
}

Copyright (C) 2014 Horizon Research Publishing All rights reserved.

\begin{abstract}
The polycrystalline undoped and Mn doped $\mathrm{ZnO} \quad\left(\mathrm{Zn}_{0.85} \mathrm{Mn}_{0.15} \mathrm{O}\right)$ nanocrystals were successfully synthesized using solid state reaction technique. The X-ray diffraction (XRD) studies of pure $\mathrm{ZnO}$ and $\mathrm{Mn}$ doped $\mathrm{ZnO}$ nanocrystals exhibit the wurtzite structure (hexagonal phase, space group $\mathrm{P} 6{ }_{3} \mathrm{mc}$ ) with high crystallinity and also without any impurity phases. Surface morphology and particle size were carried out using transmission electron microscopy (TEM). It shows that these nanoparticles are of hexagonal phase $\mathrm{ZnO}$ mostly in spherical shape with average diameter of the nanocrystals were in the range $30-100 \mathrm{~nm}$. The magnetic measurements by vibrating sample magnetometer (VSM) clearly indicate that the pure $\mathrm{ZnO}$ nanocrystals are in ferromagnetic nature and $\mathrm{Mn}$ doped $\mathrm{ZnO}$ nanocrystals exhibit co-existence of paramagnetic and ferromagnetic behavior at room temperature.
\end{abstract}

Keywords DMS, ZnO, Nanocrystals, Magnetization

\section{Introduction}

Zinc oxide $(\mathrm{ZnO})$ is an excellent electronic and photonic material having a wide bandgap $\left(E_{\mathrm{g}} \approx 3.27 \mathrm{eV}\right)$, a large exciton binding energy of $60 \mathrm{meV}$, high chemical stability, good piezoelectric properties, nontoxicity, and biocompatibility. The novel properties of nanoscale zinc oxide particles have found applications in a variety of applications such as luminescence [1-3], varistors [4, 5], solar cells [6], gas sensors [7, 8], etc.. Previously, $\mathrm{ZnO}$ nanoparticles have been prepared by techniques such as the sol-gel method [7-9], precipitation [10, 11], thermal decomposition [12,13], hydrothermal synthesis [14, 15], and spray pyrolysis [16]. However, all of these approaches use calcination or sintering. Moreover, most of them need complex apparatus, or processing, and in many cases they involve toxic reagents or additives. The relatively high temperature, complexity and toxicity of these techniques restrict their wide spread application.

Therefore, the efforts of seeking nontoxic, simple, low-cost and high-yield synthetic methods for preparing nanometer materials are being keenly pursued.

The origin of ferromagnetic behavior in Mn-doped $\mathrm{ZnO}$ is far from being understood with some research groups have claimed that ferromagnetism in TM-doped $\mathrm{ZnO}$ is external and comes from impurities [17], while other groups have reported that ferromagnetism in the same TM-doped $\mathrm{ZnO}$ prepared using the same preparation method is intrinsic to the ZnO:TM matrix [18]. However, in addition to the transition metal doping effect, structural defects such as oxygen vacancies were proposed to influence the ferromagnetic state of the oxide Diluted Magnetic Semiconductors (DMS) [19]. Recently, a number of experiments shown the correlation between the ferromagnetic behavior and the concentration of structural defects, either $\mathrm{Zn}$ interstitials [20] or oxygen vacancies [21] incorporated into the $\mathrm{ZnO}$ host lattice giving evidence that ferromagnetism in $\mathrm{ZnO}: \mathrm{Mn}$ is mediated by donor-bound carrier

Grinding processing has been routinely used as a scalable physical technique to directly break bulk materials to form fine particles upto nanoscale. In the present study, we use conventional solid state reaction technique for synthesis of $\mathrm{Zn}_{1-\mathrm{x}} \mathrm{Mn}_{\mathrm{x}} \mathrm{O}$ nanoparticles owing to its simplicity, low cost, easy handling and low temperature with controlled average grain size. The structural and magnetic properties were investigated using X-ray diffraction (XRD), Transmission electron microscopic (TEM) and Vibrating sample magnetometer (VSM).Such results are reported in this paper qualitatively and quantitatively.

\section{Experimental Details}

The samples $\mathrm{Zn}_{1-\mathrm{x}} \mathrm{Mn}_{\mathrm{x}} \mathrm{O}$ with composition ( $\mathrm{x}=0.00$ and 0.15 ) were synthesized by conventional solid state route. 
Appropriate amount of $\mathrm{ZnO}$ and $\mathrm{MnO}_{2}$ were mixed and ground in an agate mortar by pestle. The resulting powder was calcined at $450^{\circ} \mathrm{C}$ for $8 \mathrm{~h}$ in air and thereafter it was furnace cooled. The resulting materials were reground and again calcined as above. After calcinations the mixture was ground and pelletized using automatic $\mathrm{KBr}$ press technosearch instruments. Finally, these pellets were sintered at $450^{\circ} \mathrm{C}$ in air for $8 \mathrm{~h}$ each followed by furnace cooling up to room temperature. The crystal structure of the sample synthesized in the present work was studied by using X-ray diffractometer (Model: PW-3710) employing $\mathrm{Cuk}_{\alpha}(\lambda$ $=1.5406 \mathrm{~A}^{\circ}$ ) radiation. To study the sample morphology, the powders were ultrasonically mixed with ethanol and suspended on a $\mathrm{Cu}$ mesh, which was the sample holder of a transmission electron microscope (TEM) operated at $200 \mathrm{kV}$. The magnetic properties of the $\mathrm{Zn}_{1-\mathrm{x}} \mathrm{Mn}_{\mathrm{x}} \mathrm{O}$ samples were investigated by vibrating sample magnetometer (VSM) (LAKE SHORE 7307 Model) at room temperature.

\section{Results and Discussion}

\subsection{Structural Properties}

Figures 1(a) and (b) respectively show the XRD pattern of the typical undoped $\mathrm{ZnO}$ and $\mathrm{Mn}$ doped $\mathrm{ZnO}$ nanocrystals. In the diffraction pattern, all the observed diffraction peaks of both samples can be indexed to the hexagonal wurtzite structure of $\mathrm{ZnO}$ (JCPDS card No 36-1451). All peak positions and relative peak intensities of the $\mathrm{ZnO}$ nanocrystals agree well with those of the standard XRD pattern and no characteristic peaks of impurities are observed, indicating that the $\mathrm{ZnO}$ nanocrystals is of high purity. The phase structure of $\mathrm{ZnO}$ nanocrystals belong to a wurtzite structure (hexagonal phase, space group $P 63 \mathrm{mc}$ ). Moreover, all diffraction peaks of the sample show stronger peak intensities, indicating that the obtained $\mathrm{ZnO}$ nanocrystals have high crystallinity. However, the cell volume of the wurtzite phase of $\mathrm{ZnO}: \mathrm{Mn}$ samples was found to shrink from $47.69\left(\mathrm{~A}^{0}\right)^{3}$ and $47.56\left(\mathrm{~A}^{0}\right)^{3}$ for pure $\mathrm{ZnO}$, possibly due to the decrease of defects which consistent with the crystals improvement for $\mathrm{Mn}$ doped as revealed from XRD spectrum as shown Fig. 1.The mean crystallite size of a powder sample was calculated from the full width at half-maximum (FWHM) of the diffraction peak according to the Scherrer equation (i.e. $D=0.9 \lambda / \beta \cdot \cos \theta$ ), where $\lambda$ - is the wave length of the $\mathrm{X}$ - ray diffraction, $\theta$ - is the diffraction angle and $\beta$ - is full width at half maximum (FWHM). The average crystalline size of pure $\mathrm{ZnO}$ and $\mathrm{Zn}_{0.85} \mathrm{Mn}_{0.15} \mathrm{O}$ nanocrystals were estimated to be about $36 \mathrm{~nm}$ and $34 \mathrm{~nm}$ respectively after appropriate background correction from $\mathrm{X}$-ray line broadening the lattice parameters evaluated from XRD data of $\mathrm{Zn}_{0.85} \mathrm{Mn}_{0.15} \mathrm{O}$ are $\mathrm{a}=3.2507 \mathrm{~A}^{0}$ and $\mathrm{c}=5.2112$ $\mathrm{A}^{0}$, which are closer to the $\mathrm{ZnO}\left(\mathrm{a}=3.2480 \pm 0.002 \mathrm{~A}^{0}, \mathrm{c}=\right.$ $5.2064 \pm 0.003 \mathrm{~A}^{0}$ ) revealing that the doping of Mn does not affect the wurtzite structure of zinc oxide.

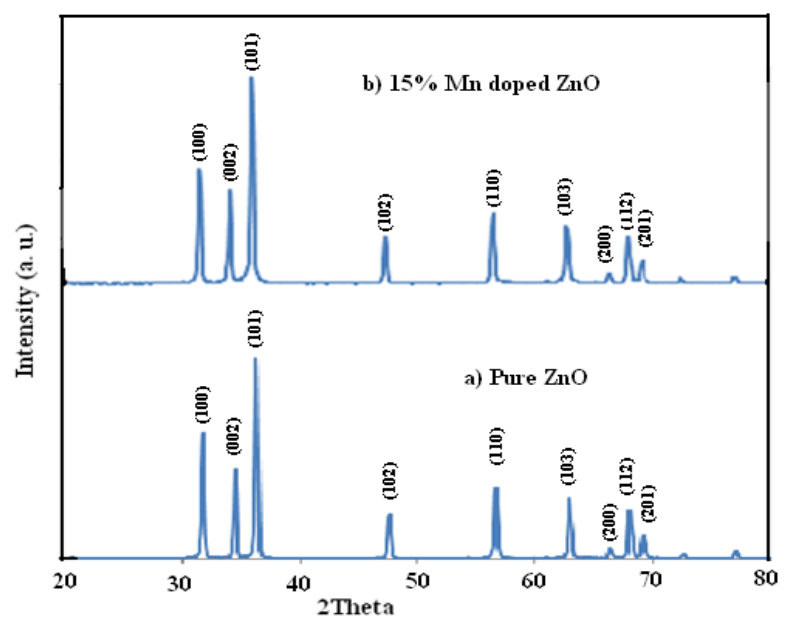

Figure 1. XRD pattern for a) pure $\mathrm{ZnO}$ and b) $\mathrm{Mn}$ doped $\mathrm{ZnO}$ $\left(\mathrm{Zn}_{0.85} \mathrm{Mn}_{0.15} \mathrm{O}\right)$ samples

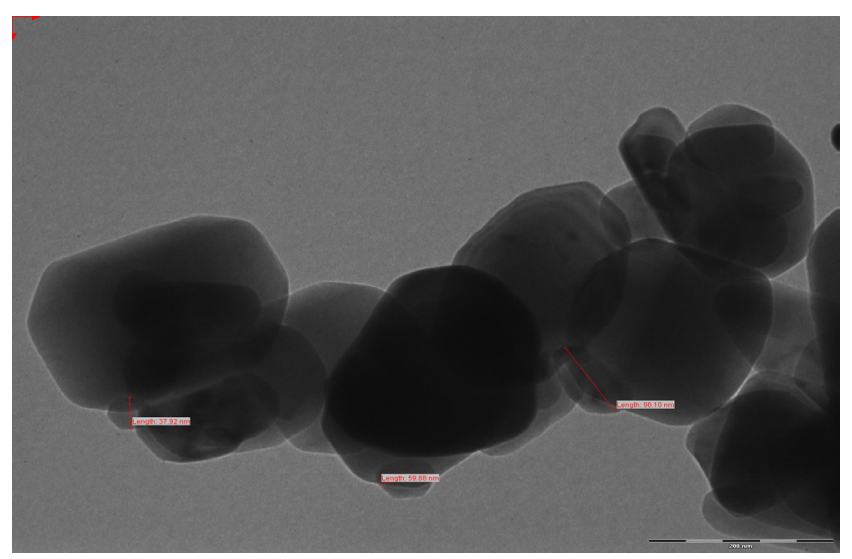

Figure 2. (a). TEM images of $\mathrm{ZnO}$ nanocrystals.

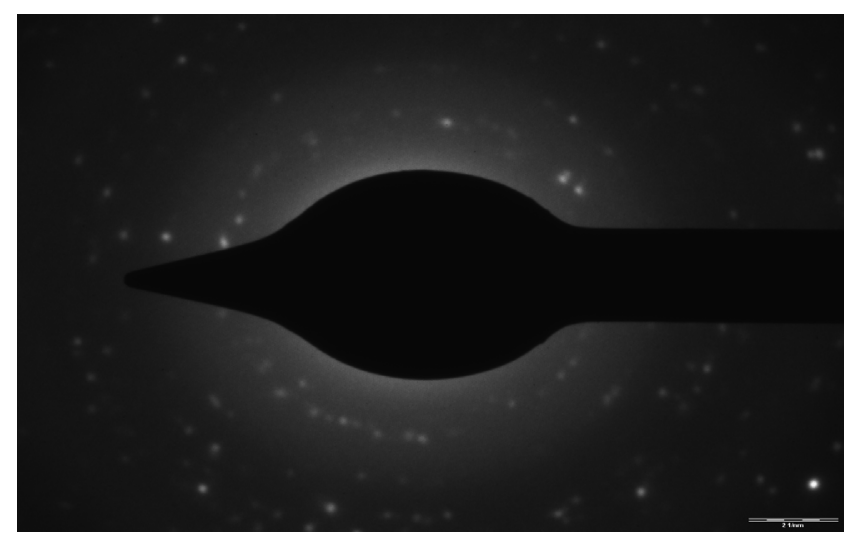

Figure 2. (b). SAED pattern of $\mathrm{ZnO}$ nanocrystals.

The particle size and morphology of a sample was characterized by transmission electron microscopy. The typical bright field TEM images for pure sample are shown in figure 2(a). The TEM study of $\mathrm{ZnO}$ nanocrystals indicates that most of the nanoparticles are nearly spherical and hexagonal shape. From the micrograph their average grain sizes observed in the range of $30-100 \mathrm{~nm}$ and the mean grain size is $35 \mathrm{~nm}$, the selected-area electron diffraction (SAED) pattern as shown in figure 2(a), taken from the TEM image as 
shown in figure 2(a). It can be indexed to the reflection of wurtzite $\mathrm{ZnO}$ structure and shows diffraction intensity associated with crystalline $\mathrm{ZnO}$, which is consistent with the XRD results. These nanoparticles have clear borders, illustrating that they are well crystallized.

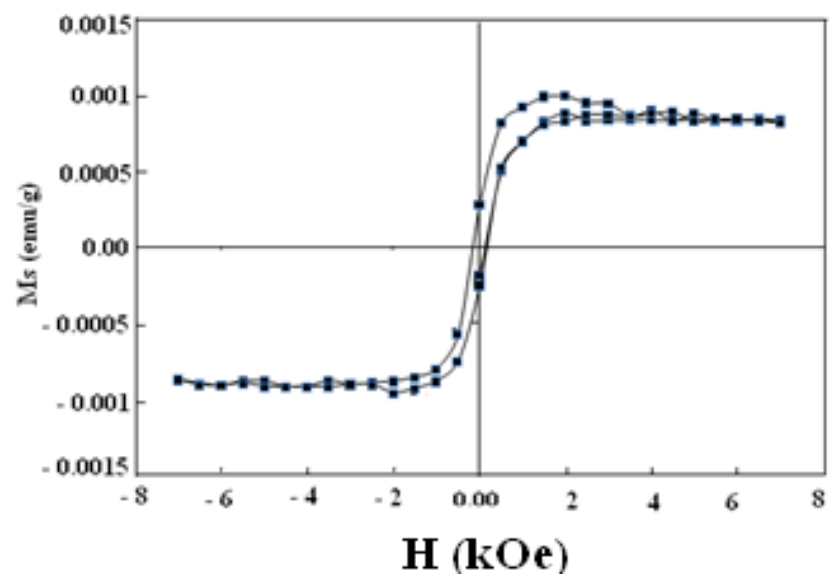

Figure 3. (a). Magnetization vs. Field curve for $\mathrm{ZnO}$ at room temperature

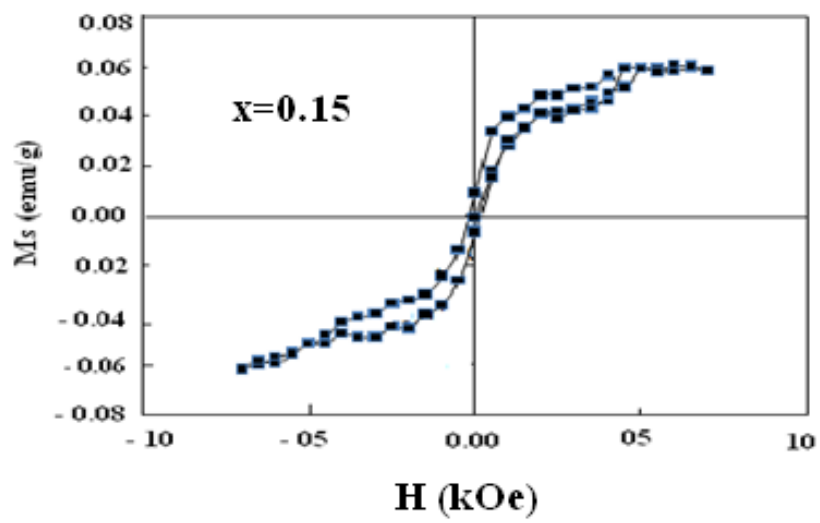

Figure 3. (b). Magnetization vs. Field curve for $\mathrm{Zn}_{0.85} \mathrm{Mn}_{0.15} \mathrm{O}$ at room temperature

\subsection{Magnetic Properties}

Figures 3(a) and 3(b) show the magnetic hysteresis M-H curves (field dependence of magnetization) for the pure $\mathrm{ZnO}$ and $\mathrm{Mn}$ substituted $\mathrm{ZnO}\left(\mathrm{Zn}_{0.85} \mathrm{Mn}_{0.15} \mathrm{O}\right)$ nanocrystals measured at room temperature. It is clear that pure $\mathrm{ZnO}$ exhibit ferromagnetic behavior and $\mathrm{Mn}$ doped $\mathrm{ZnO}$ sample shows paramagnetism and ferromagnetism behaviour. Further, it is evident from figures that the saturation magnetization (Ms) increases as Mn doping. The saturation magnetization (Ms) values obtained from hysteresis loops are $9.97 \times 10^{-4} \mathrm{emu} / \mathrm{g}$ for pure $\mathrm{ZnO}$ and $6.09 \times 10^{-4} \mathrm{emu} / \mathrm{g}$ for $\mathrm{Mn}$ doped $\mathrm{ZnO}$ nanocrystals samples. The values of coercivity $\left(\mathrm{H}_{\mathrm{c}}\right)$ both samples are $280 \mathrm{G}$ for pure $\mathrm{ZnO}$ and 178 $\mathrm{G}$ for $\mathrm{Mn}$ doped $\mathrm{ZnO}$ nanocrystals. The $\mathrm{ZnMnO}$ nanocrystals can also show FM properties by carefully control over doping speciation and concentration. Several assumptions have been addressed at up till now: the role of the secondary phase, the connection between defects and magnetism, oxygen vacancy, etc [22-24]. In order to understand the magnetic behavior of the samples, it is not clear whether the ferromagnetism originates from secondary phase formation, because (a) metallic $\mathrm{Mn}$ is antiferromagnetic and (b) nearly all of the possible Mn-based binary and ternary oxide candidates are antiferromagnetic except $\mathrm{Mn}_{3} \mathrm{O}_{4}$ which is ferromagnetic with a curie temperature of only $46 \mathrm{~K}$ in thin film [25]. Further, Our results show that the pure $\mathrm{ZnO}$ nanocrystals have ferromagnetism due to the alternation of the semiconductor electronic configuration can be present in the absence of magnetic ions [26] and also $\mathrm{Mn}$ doped $\mathrm{ZnO}$ nanocrystals clearly indicate the coexistence of para and ferromagnetic nature. These results are consistent with the more recent study [27], in which ferromagnetism is mediated by shallow donor electrons that form bound magnetic polarons, which overlap to create a spin split impurity band. In $\mathrm{ZnO}$, slowly $\mathrm{Mn}$ doping usually results in $\mathrm{n}$ - type $\mathrm{ZnO}$. It is found that when $\mathrm{Mn}$ concentration enhances in $\mathrm{ZnO}$ nanocrystals upto $15 \%$ there is coexistence of para and ferromagnetism but in reported literature system shows paramagnetism [27]. On the other hand, intrinsic defects, oxygen vacancy, unreacted $\mathrm{MnO}_{2}$ [28], such as act as shallow donors in $\mathrm{ZnO}$ [10]. Then, according to Coey et al. [19], the room temperature ferromagnetism in $\mathrm{Zn}_{1-\mathrm{x}} \mathrm{Mn}_{\mathrm{x}} \mathrm{O}(\mathrm{x}=0.15)$ nanocrystals would originates from the long range $\mathrm{Mn}^{2+}-\mathrm{Mn}^{2+}$ ferromagnetic coupling mediated by shallow donor electron.

\section{Conclusion}

Nanocrystals of $\mathrm{Zn}_{1-\mathrm{x}} \mathrm{Mn}_{\mathrm{x}} \mathrm{O}$ ( $\mathrm{x}=0.00$ and 0.15 ) have been successfully prepared using solid state reaction technique. Microstructure analysis confirms the single phase hexagonal wurtzite structure for pure $\mathrm{ZnO}$ and $\mathrm{Mn}$ doped $\mathrm{ZnO}$ nanocrystals respectively. The particle size and morphology of the $\mathrm{Zn}_{1-\mathrm{x}} \mathrm{Mn}_{\mathrm{x}} \mathrm{O}$ nanocrystals have been determined by transmission electron microscopy. It indicates that the particles size lies in the range $30-100 \mathrm{~nm}$, which is consistent with the result obtained from the XRD data. The selected-area electron diffraction (SAED) pattern shows that the nanocrystals are in crystalline nature. Magnetic hysteresis curves show that the co-existence of paramagnetic and ferromagnetic behavior in $\mathrm{Mn}$ doped $\mathrm{ZnO}$ nanocrystals but in pure $\mathrm{ZnO}$ nanocrystals show only ferromagnetic phase exist even at room temperature may due to alteration of semiconductor electronic configuration.

\section{REFERENCES}

[1] A. van Dijken, E. A. Meulenkamp, D. Vanmaekelbergh, A. Meijerink, J. Luminesc. 87-89, 454 (2000).

[2] L. Guo, S. H. Yang, C.L. Yang, P. Yu, J. N. Wang, W. K. Ge, 
G. K. L. Wong, Chem. Mater. 12, 2268 (2000).

[3] Y. Feng, Y. X. Zhou, Y. Q. Liu, G. B. Zhang, X. Y. Zhang, J. Luminesc. 119/120, 233 (2006).

[4] S. Hingorani, V. Pillai, P. Kumar, M. S. Multani, D. O. Shah, Mater. Res. Bull. 28, 1303.(1993).

[5] S. C. Pillai, J. M. Kelly, D. E. McCormack, P. O’Brien, R. Ramesh, J. Mater. Chem. 13, 2586 (2003).

[6] W. J. E. Beek, M. M. Wienk, R. A. J. Janssen, Adv. Mater. 16, 1009 (2004).

[7] M. Epifani, R. Diaz, J. Arbiol, E. Comini, N. Sergent, T. Pagnier, P. Siciliano, G. Taglia, J. R. Morante, Adv. Funct. Mater. 16, 1488 (2006).

[8] H. X. Tang, M. Yan, X. F. Ma, H. Zhang, M. Wang, D. R. Yang, Sens. Actuators B 113, 324 (2006).

[9] J. H. Lee, K. H. Ko, B.O. Park, J. Cryst. Growth 247, 119 (2003).

[10] L. N.Wang, M. Muhammed, J. Mater. Chem. 9, 2871 (1999).

[11] J. E. Rodr'iguez-Pa'ez, A. C. Caballero, M. Villegas, C. Moure, P. Dur'an, J. F. Fern'andez, J. Eur. Ceram. Soc. 21, 925 (2001).

[12] Y. Yang, H. L. Chen, B. Zhao, X. M. Bao, J. Cryst. Growth 263, 447 (2004).

[13] P. D. Cozzoli, M. L. Curri, A. Agostiano, G. Leo, M. Lomascolo, J. Phys. Chem. B 107, 4756 (2003).

[14] H. Y. Xu, H. Wang, Y. C. Zhang, W. L. He, M. K. Zhu, B. Wang, H. Yan, Ceram. Int. 30, 93 (2004).

[15] K. Sue, K. Kimura, K. Arai, Mater. Lett. 58, 3229 (2004).
[16] T. Tani, L. Madler, S.E. Pratsinis, J. Nanopart. Res. 4, 337 (2002)

[17] Y. M. Kim, M. Yoon, I. -W. Park, Y. J. Park, and J. H. Lyou, Solid State Commun. 129, 175 (2004).

[18] L. Q. Liu, B. Xiang, X. Z. Zhang, Y. Zhang, and D. P. Yu, Appl. Phys. Lett. 88, 63104 (2006).

[19] J. M. D. Coey, M. Venkatesan, and C. B. Fitzgerald, Nat. Mater. 4, 173 (2005).

[20] K. R. Kittilstved, W. K. Liu, and D. R. Gamelin, Nat. Mater. 5, 291 (2006).

[21] N. H. Hong, J. Sakai, N. T. Huong, N. Poirot, and A. Ruyter, Phys. Rev. B 72, 45336 (2005).

[22] S. J. Pearton, D. P. Norton, and K. Ip. Progress in Mater. Sci. $50,293(2005)$

[23] M. Venkatesan, C. B. Fitzgerald, and J. M. D. Coey, Nature 430, 630 (2004)

[24] O. Eriksson, L. Bergqvist, and B. J. Sanyal, Phys. Condens. Matter. 16, S5481.

[25] A. Chartier, P. D. Arco, and R. Dovesi, Phys. Rev. B 60, 14042 (1999).

[26] M. A. Garcia J. M. Merino, E. Fernandez Pinel, A. Quesada, J. de la Venta, M. L. Ruiz Gonzalez, G. R. Castro, P. Crespo, J. Liopis, J. M. Gonzalez-Calbet, and A. Hernando, Nano letters 7, 1489 (2007).

[27] H. Gui-jun, W. Jin.bin, Z. Xiang-li, Z. Gong-cheng, and Y. Hal-long, Optoelectronics Letts. 2, 6 (2006).

[28] J. L. Costa-Kramer, F. Briones, J. F. Fernandez, A. C. Caballero, M. Villegas, M. Daz, M. A. Garcia and A. Hernando, Nanotechnology 16, 214-218 (2005). 